


\section{Models of the Labyrinth}

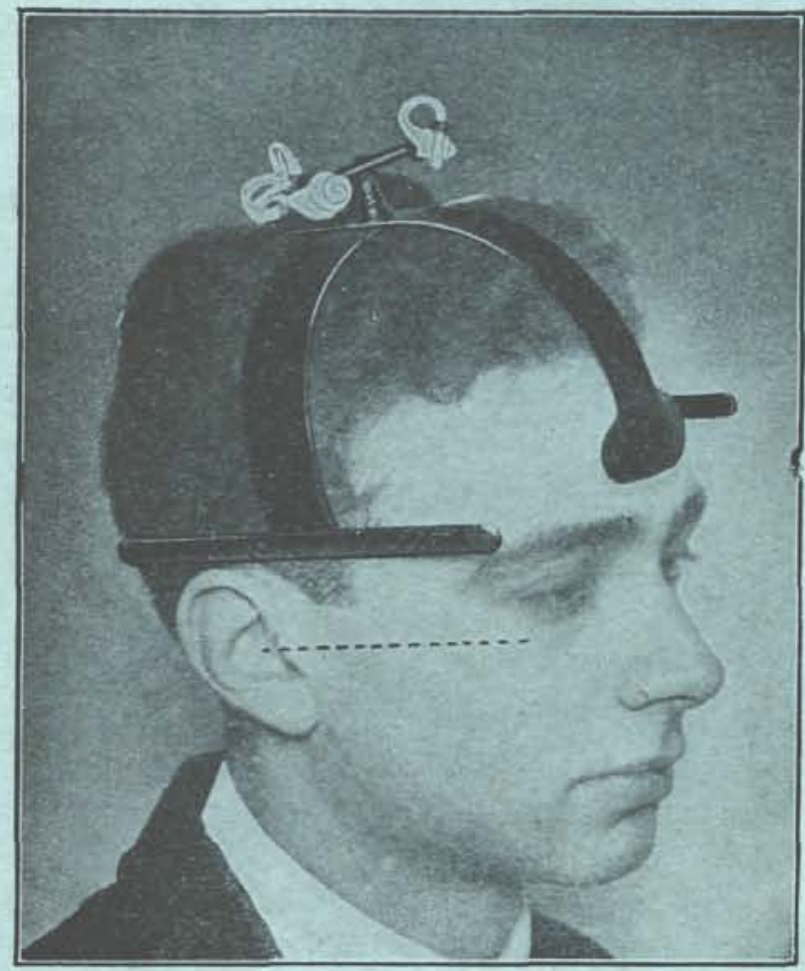

These models (King's College Hospital pattern) were devised by

Mr A. H. CHEATLE and

Mr NEGUS

for teaching purposes and for investigating labyrinthine diseases.

The pointers on the Head frame lie parallel with the Frankfort plane, so that when the frame is on the head the models lie in correct orientation in all respects. The patient's head can be put in any position and the exact relations of each of the canals are seen; rotation and caloric tests can be carried out with the frame in position.

\section{Furgical Fnstrument IDanufacturers}

Established over Sixty Years
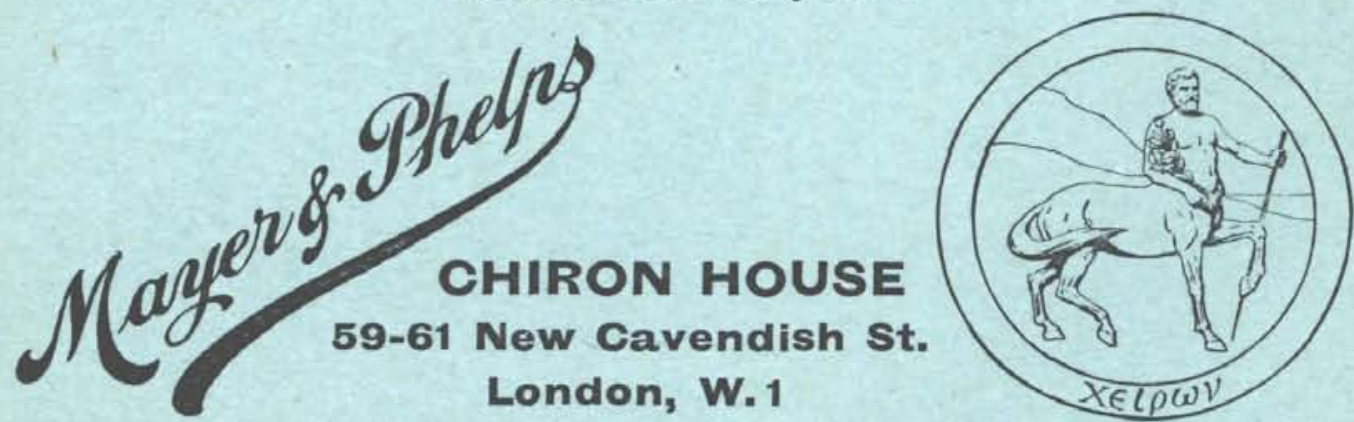